\title{
Editorial
}

\section{Integrated ecological indicators for sustainable urban ecosystem evaluation and management}

\section{Background}

The theories and insights of ecological science have already arisen in the last century but somehow they are shunned in terms of solving urban environmental problems (Grimm, 2008). However, in the face of eco-environmental problems caused by urbanization, the ecological perspectives and ad-hoc solutions have been highlighted and matured over the last decade. Recently, increasing numbers of ecologists have collaborated with other scientists, planners, and engineers to evaluate and even regulate urban ecosystems and the associated economic activities (Fath and Müller, 2010; Chen and Chen, 2012; Chen et al., 2014a). Cities themselves can represent microcosms of global environment change, making them informative test cases for understanding socio-ecological system sustainability and the regulation and management of human perturbations (Wang and Yan, 1998; Wang et al., 2011; Chen and Yang, 2013). Using appropriate methods and indicators based on interdisciplinary effect of modeling and assessment is one of most important paces to do so (Jørgensen et al., 2005; Müller and Lenz, 2006).

To learn from the insights of global cities, share best practices internationally, and discuss how cities and regions can play a leading role in creating a sustainable society, we co-organized the International Workshop on Ecological Modelling for Low Carbon Cities \& ISEM-Pacific Annual Meeting in Beijing during March 19th-20th, 2013 as an attempt to provide a forum to discuss and advance issues relevant to theories, methodologies and cases of urban and regional sustainability and their relevance to ecological indicators.

Meanwhile, to solve the ecological and environmental issues of coordinated urban-regional development, we also invite some research groups to explore the integrated water resource management of the river basin based on the current research of observation, experiments, simulation and scenario analysis in the "Heihe River Basin Major Research Plan" supported by the National Natural Science Foundation of China. Led by the principal investigator, Prof. Xiangzheng Deng, the National Major Scientific Research Program, entitled "Decision Support System for the Integrated Water Resource Management in Heihe River Basin (No. 91325302), has thereby been launched in 2013. A conceptual framework has been built by compiling water resource extended input-output (IO) table compilation at county level and incorporating the Computable General Equilibrium (CGE) model into integrated water management studies (Deng et al., 2014a). The compiled IO table includes resources and environment accounts with multiple datasets which contains the spatio-temporal data of water and land resources, ecology, and social economy in the regional extent (Deng et al., 2014b). By doing this, we aim to probe into the regulation measures to optimize the configuration of water resources and realize the integration of the fundamental research innovation and the management practice, thus providing reasonable decision support for the nexus of water security, ecological security and sustainable socio-economic development of cities and regions.

\section{Papers in this issue}

Following the theory-method-case paradigm, we propose four subsections composing the special issue as below:

\section{(1) Theories and metaphysics}

Kennedy et al. (2014) introduce a new multi-layered indicator set for urban metabolism studies, which is designed to gather information on the definition, biophysical characteristics, and metabolic flows of megacities. The role of utilities in the provision of services and regulatory actions that, along with public governance, may influence (and/or control) the urban metabolism is also addressed. Two methodologies to define megacity boundaries are compared, showing that further investigation is needed to establish a baseline for comparison of urban metabolism data. Zucaro et al. (2014) evaluate the interlinkages and synergies among different resources and performance patterns in the city of Rome by means of decomposition equations in order to identify the major drivers of change in the investigated period as well as future low-resource scenarios. The effects associated with the emissions are evaluated with a special focus on global warming and acidification potential. The changes in the urban metabolism occurred are also analyzed considering the variation of different inputs necessary to drive the city, indicating that the increased fraction of imports are the major drivers of such unsustainability pattern. Feng et al. (2014) focused on the spatial distribution of production activities leading to $\mathrm{CO}_{2}$ emissions across China as a consequence of final consumption in four Chinese mega cities including Beijing, Shanghai, Tianjin, and Chongqing. The outsourcing research based on multi-regional input-output 
analysis show that urban consumption not only causes a large amount of emissions within its territory, but also imposes even much more emissions to its surrounding provinces via interregional supply chains. Regarding the key role of urban consumption in climate change mitigation, it is suggested to better inform such policies for cities to use consumption-based emission accounting allowing them to recognize and reduce carbon emissions within city boundaries and along the global supply chains at least costs. Shao et al. (2014a) proposed a comprehensive framework with a systems method as a combination of process and input-output analyses to analyze the embodied ecological elements as natural resources and environmental emissions of wastewater treatment. Two representative ecological elements, i.e., greenhouse gases emissions and solar emergy of alternative wastewater treatment systems, i.e., a traditional activated sludge wastewater treatment plant and a constructed wetland have been taken into consideration. Five ecological indicators have accordingly been calculated and compared to assess the impact on climate change and resources utilizing style of the case systems. Zhao et al. (2014) explored the influencing factors of population, affluence, urbanization level, and diet structure on agriculture products-related water footprint change based on an extended STIRPAT model. Empirical results reveal that the all the examined factors as positive driving forces have pushed forward Chinese agricultural sector water footprint. Furthermore, the absolute values of normalized coefficients indicate that population has the largest positive contribution to increase the Chinese agricultural water footprint. Based on the Multi-Scale Integrated Analysis of Societal and Ecosystem Metabolism (MuSIASEM), Mayumi and Giampietro (2014) outline a general energy accounting scheme and its indicators to go beyond the traditional monistic methodology, characterizing the performance of the energy and mining sector as an elaboration of the supply side of energy accounting. A general energy accounting scheme and its derived set of indicators is then analyzed to examine the basic assumptions and energy transformation process using the flow-fund representation originally developed by Georgescu-Roegen. Arodudu et al. (2014) combine GIS with life cycle assessment methodologies to identify and estimate bioenergy potential of green roofs and other bioenergy options within urban areas. Net Energy Gain (NEG) and Energy Return on Energy Invested (EROEI) are used as thermodynamic indicators to assess the sustainability of bioenergy sources within urban built-up spaces by comparing their energy efficiencies and their contributions to set renewable energy targets in one frame. The conversion factors and assumptions used in the course of estimating the bioenergy potentials are expected to be further applied in other regions with similar urban patterns and social arrangements. The findings show that biomass flows from urban settings might be capable of playing significant roles in meeting local energy demands, and renewable energy/carbon emission targets, depending on the peculiarities of the local or regional energy landscape in focus. Fang et al. (2014) investigate the socio-economic water system using network analysis developed originally for ecosystems, providing a novel perspective and methodology for assessing the structure and efficiency of water utilization system with a whole perspective. Structural and throughflow indicators, such as Finn Cycling Index. (FCI), Indirect Effects Ratio (IER), and Aggradation are devised to describe the water utilization in different perspectives of the system's efficiency change over time. A case study of Heihe River Basin demonstrates that the structure has influenced the cycling and indirect flows, while from a throughflow perspective, the system depends on large boundary inputs of fresh water.

\section{(2) Methods and metrics}

Bae et al. (2014) examine community concordance among diatoms, macroinvertebrates and fish in minimally disturbed streams on four nested spatial scales in Korea, thus contributing to the study of the metrics for sustainable urban ecosystem evaluation. The results based on non-metric multidimensional scaling show that diatoms, macroinvertebrates and fish displayed consistent patterns that are strongly structured along an altitude gradient at the national scale. Also, community concordance among diatoms, macroinvertebrates and fish would be different according to spatial scales and even in the same scales and that use of a representative taxon to assess ecological integrity should be applied with caution. Li et al. (2014a,b) put forward measurement of ecosystem services including space, time, equivalent, pattern and order metrics for urban areas. Case studies of urban land evaluation, ecological space accounting, water and energy equivalents assessment are also performed for Changzhou city of China. Zhang and Chen (2014) present a detailed bottom-up estimation and comparison analysis of China's $\mathrm{CH}_{4}$ and $\mathrm{CO}_{2}$ emissions, figuring out that China's $\mathrm{CH}_{4}$ emissions are of comparable importance to the $\mathrm{CO}_{2}$ emissions at the national and regional levels, and there are remarkable regional disparities on the potential reduction capability of greenhouse gas emissions among the eastern, central and western regions. Yao et al. (2014) propose a metric of effective green equivalent (EGE), which is defined as the area of green space multiplied by corrected coefficients of quality and accessibility. Two city-level indicators are also developed for Beijing, confirming that the EGE values of local individual residents follow a normal distribution. Han et al. (2014a,b) propose the concept of complex ecological niche (CEN) involving three groups of key elements, i.e., natural environment, economy and social culture, and design an indicator system for the urban population with three sub-CENs as second-level indicators, and another indicator evaluating the balance degree among three sub-CENs. A case study of 220 Chinese cities during 2000-2011 implies that there is a threshold in the development process of the CEN, which differentiates the negative and positive impacts upon urban agglomeration. Dean et al. (2014) establish an indicator framework for evaluating business parks, within which four categories are relevant to their success: Environment, Facilities, Business Synergism, and Green Image. Considering the Eco-smart Corporate Communities that have incorporated environmentally friendly practices into their design and operations, an Expanded Business Operations Model is conceptualized to describe these communities with the ultimate goal of positively impacting the local and larger communities. To provide new evidence in favor of EKC hypothesis that claims a trade-off between growth and environmental quality at least in the short-run, Tan et al. (2014) conduct a study for Singapore by analyzing the data on $\mathrm{CO}_{2}$ emissions, energy consumption and per capita GDP for 1975-2011 by means of cointegration and causality technique, which indicates that a significant rise in $\mathrm{CO}_{2}$ emissions as GDP rose over the years confirming a short-run trade-off between environment and growth. The causality analysis further proves that $\mathrm{CO}_{2}$ emissions indeed have caused decline in Singapore's growth, manifesting that strict regulatory regimes on environmental protection in the city-state should remain in force. Based on a global multi-region input-output model, Yu et al. (2014) assess the unequal exchange between China and the rest of world (186 countries) using value added and four environmental indicators associated with China's trade relations with the outside world and find that, developed regions externalize environmental impacts through importing goods produced in China. By contrast, less developed regions, such as Southeast Asia, South 
Asia and Africa, export large quantities of goods and associated $\mathrm{SO}_{2}$ and $\mathrm{CO}_{2}$ emissions, land and water to China, but only gain relatively small shares of economic values in exchange.

(3) Real cases

Li and Chen (2014) employ a hybrid method to evaluate the water footprint of gaming industry in water scarce Macao, based on the latest statistics and most exhaustive embodied water intensity databases. The case shows that direct water use only accounts for extremely small fraction of the gaming industry's water footprint, implying that the exchange of water embodied in product and service between different sectors is a useful mean to satisfy individual sector's demand for water resources. Li et al. (2014a,b) take the inner city of Shanghai as a case and investigate the discrepant impacts of land use and land cover on surface temperature (LST). The key factors affecting urban LST are found to be not only land cover patterns, but also other anthropogenic forces. Meanwhile, at fine spatial scales, information on land use is more meaningful than that of land cover to quantify the impacts of urbanization on ecosystems. Han et al. (2014a,b) made efforts to analyze the structure engineering of the landmark buildings in Beijing through a series of emergy-based indicators to reflect its eco-efficiency and the role of commercial construction engineering in urban economy. The results show that, even though a low dependence on local renewable resources and a heavy environmental stress on the environment are observed in the case engineering, its renewability still can be improved through some specific measures such as manufacturing process improvement and raw material source adjustments. To appraise the ecological performance of integrated biogas system, Wu et al. (2014a,b); Chen et al. (2014b) undertake an emergy accounting for a typical pig-biogas-fish system in Hubei province of China. The case study reveals that in a 20 -year designed lifetime scenario, nearly $95 \%$ of the total emergy inputs for the investigated system are attributed to purchase social resources. Compared with the Chinese conventional agriculture system, the integrated biogas system shows a higher sustainability. Guo et al. (2014) employs an ecological input-output model to reveal the impact of domestic consumption and international trade on cultivated land distributions in China during 1987-2007. According to the high-sectoral-resolution dataset, Agriculture and Food Processing are identified as the two key sectors that contribute the largest volumes of embodied cultivated land to meet household food demand in 2007. When China is shown to be a net embodied cultivated land exporter throughout the concerned years, the variation of embodied cultivated land balance is closely related to the country's international trade pattern. To assess the ecological risk and to understand the transport processes of heavy metals in an agricultural ecosystem, Liu et al. (2014) investigate the concentrations of heavy metals in agricultural soils ( $\mathrm{As}, \mathrm{Cd}, \mathrm{Cr}, \mathrm{Cu}, \mathrm{Mn}, \mathrm{Ni}, \mathrm{Pb}, \mathrm{Zn}$ ) and in wheat plants at different stages of growth ( $\mathrm{Cd}, \mathrm{Pb}, \mathrm{Zn})$ near the Fengfan leadacid battery factory in Baoding city of China, showing that the potential health risks due to the cumulative risk of all heavy metals through the consumption of wheat berries exceed unity for rural inhabitants but not notable for urban inhabitants.

(4) Others

Wu et al. (2014a,b); Chen et al. (2014b) use SPOT-VGT imagery to monitor vegetation cover change in the Poyang Lake. Using Normalized Difference Vegetation Index (NDVI) as an indicator to reveal vegetation change of the wetland, the correlation coefficients between a time series of NDVI and different types of migratory birds are obtained. The results demonstrate that wetland is positively correlated with bird population of all species, while cropland is negatively correlated. Han et al. (2014a,b) adopt a bibliometric approach to quantitatively evaluate global scientific research on hydropower sustainable development with a long time span ranging from 1991 to 2012. By synthetically analyzing the keywords, the dominant hotspots of hydropower sustainable research are found to be "Turkey", "Eco-", "Small hydro-", and "Fish". Along with a comparable number of publications to the United State, the keyword "Turkey" has exhibited a notable increase since 2000 , revealing its predominance in the research of hydropower sustainable development. Shao et al. (2014b) present the analytical procedures for determining the key quantity of Taylor dispersivity for typical wetlands with free water surface, respectively as the steady flow wetlands, tidal flow wetlands, and the two-layer flow wetlands. Critical length and duration of the contaminant cloud in the steady flow wetlands are analyzed based on the obtained Taylor dispersivity. Results show that in contrast to the temporary, localized influence of COD on water quality, the heavy metal $\mathrm{Pb}$ can give rise to more severe damage. Wang et al. (2014) analyze the environmental dispersion in a three-layer wetland in terms of the longitudinal evolution of the lateral mean concentration. An environmental dispersion model for the mean concentration in the three-layer wetland is set up as an extension of Taylor's classical formulation. The analytical results illustrate the effect of dimensionless parameters on the environmental dispersivity. Other related indicators for urban water quality assessment in three-layer wetlands, i.e., the critical length and duration of the contaminant cloud of typical contaminant constituents are also characterized.

The Guest Editors would like to express their high appreciation to the authors and reviewers for their great contribution to this special issue.

\section{Acknowledgements}

This work was supported by the Major Research plan of the National Natural Science Foundation of China (No. 91325302), Fund for Creative Research Groups of the National Natural Science Foundation of China (No. 51121003), National Natural Science Foundation of China (No. 41271543), and Specialized Research Fund for the Doctoral Program of Higher Education of China (No. 20130003110027).

\section{References}

Arodudu, O., Ibrahim, E., Voinov, A., Duren, I.V., 2014. Exploring bioenergy potentials of built-up areas based on NEG-EROEI indicators. Ecol. Indic. 47, 67-79.

Bae, M.J., Li, F.Q., Kwon, Y.S., Chung, N., Choi, H., Hwang, S.J., Park, Y.S., 2014. Concordance of diatom, macroinvertebrate and fish assemblages in streams at nested spatial scales: implications for ecological integrity. Ecol. Indic. 47, 89-101.

Chen, B., Yang, Z.F., 2013. Modelling for multi-scale ecosystems in the context of global climate change. Ecol. Model. 252, 1-2.

Chen, S.Q., Chen, B., 2012. Network environ perspective for urban metabolism and carbon emissions: a case study of Vienna, Austria. Environ. Sci. Technol. 46, 4498-4506.

Chen, S.Q., Chen, B., Fath, B.D., 2014a. Urban ecosystem modeling and global change: potential for rational urban management and emissions mitigation. Environ. Pollut. 190, 139-149.

Chen, X.L., Xia, X.H., Hayat, T., Alsaedi, A., 2014b. Bibliometric indicators for sustainable hydropower development. Ecol. Indic. 47, 231-238.

Dean, C.A., Fath, B.D., Chen, B., 2014. Indicators for an expanded business operations model to evaluate eco-smart corporate communities. Ecol. Indic. 47, 137-148.

Deng, X., Wang, Y., Wu, F., Zhang, T., Li, Z., 2014a. Integrated River Basin Management. Springer.

Deng, X., Zhang, F., Wang, Z., Li, X., Zhang, T., 2014b. An extended input output table compiled for analyzing water demand and consumption at county level in China. Sustainability 6, 3301-3320.

Fang, D.L., Fath, B.D., Chen, B., Scharler, U.M., 2014. Network environ analysis for socio-economic water system. Ecol. Indic. 47, 80-88.

Fath, B.D., Müller, F., 2010. Long-term ecosystem dynamics: theoretical concepts of environmental change. In: Müller, F., Baessler, C., Schubert, H., Klotz, S. (Eds.), Long-term Ecological Research between Theory and Application. SpringerVerlag, Dordrecht, Heidelberg, London, New York, pp. 27-38. 
Feng, K.S., Hubacek, K., Sun, L.X., Liu, Z., 2014. Consumption-based $\mathrm{CO}_{2}$ accounting of China's megacities: the case of Beijing, Tianjin, Shanghai and Chongqing. Ecol. Indic. 47, 26-31.

Grimm, N.B., 2008. Global change and the ecology of cities. Science 319, 756-760. Jørgensen, S.E., Costanza, R., Xu, F., 2005. Handbook of Ecological Indicators for Assessment of Ecosystem Health. CRC Press, Boca Raton, FL.

Guo, S., Yan, G., Shen, Q.P., Chen, Z.M., Yu, R., 2014. Embodied cultivated land use in China 1987-2007. Ecol. Indic. 47, 198-209.

Han, B.L., Wang, R.S., Tao, Y., Gao, H., 2014a. Urban population agglomeration in view of complex ecological niche: a case study on Chinese prefecture cities. Ecol. Indic. 47, 128-136.

Han, M.Y., Sui, X., Huang, Z.L., Wu, X.D., Han, M.Y., Shao, L., Li, J.S., Guo, S., Meng, J., Ahmad, B., Hayat, T., Alsaadi, F., Ji, X., Alsaedi, A., Chen, G.Q., 2014b. Emergybased hybrid evaluation for commercial construction engineering: a case study in BDA. Ecol. Indic. 47, 179-188.

Kennedy, C., Stewart, I., Ibrahim, N., Facchini, A., Mele, R., 2014. Developing a multilayered indicator set for urban metabolism studies in megacities. Ecol. Indic. 47, 7-15.

Li, F., Wang, R.S., Hua, D., Ye, Y.P., Yang, W.R., Liu, H.X., 2014a. Measurement methods and applications for beneficial and detrimental effects of ecological services. Ecol. Indic. 47, 102-111.

Li, J.S., Chen, G.Q., 2014. Water footprint assessment for service sector: a case study of gaming industry in water scarce Macao. Ecol. Indic. 47, 164-170.

Li, W.F., Bai, Y., Chen, Q.W., He, K., Ji, X.H., Han, C.M., 2014b. Discrepant impacts of land use and land cover on urban heat islands: a case study of Shanghai, China. Ecol. Indic. 47, 171-178.

Liu, G.N., Yu, Y.J., Hou, J., Xue, W., Liu, X.H., Liu, Y.Z., Wang, W.H., Alsaedi, A., Hayat, T., Liu, Z.T., 2014. An ecological risk assessment of heavy metal pollution of the agricultural ecosystem near a lead-acid battery factory. Ecol. Indic. 47, 210-218.

Mayumi, K., Giampietro, M., 2014. Proposing a general energy accounting scheme with indicators for responsible development: beyond monism. Ecol. Indic. 47, 50-66.

Müller, F., Lenz, R., 2006. Ecological indicators: theoretical fundamentals of consistent applications in environmental management. Ecol. Indic. 6, 1-5.

Shao, L., Jiang, Z., Li, Z., Chen, B., Hayat, T., Ahmad, B., Alsaedi, A., 2014a. Indicators for contaminant transport in wetlands. Ecol. Indic. 47, 239-253.

Shao, L., Chen, G.Q., Hayat, T., Alsaedi, A., 2014b. Systems ecological accounting for wastewater treatment engineering: method, indicator and application. Ecol. Indic. 47, 32-42.

Tan, F., Lean, H.H., Khan, H., 2014. Growth and environmental quality in Singapore: is there any trade-off? Ecol. Indic. 47, 149-155.

Wang, P., Li, Z., Huai, W.X., Chen, B., Li, J.S., Hayat, T., Alsaedi, A., Chen, G.Q., 2014. Indicators for environmental dispersion in a three-layer wetland: extension of Taylor's classical analysis. Ecol. Indic. 47, 254-269.
Wang, R.S., Yan, J.S., 1998. Integrating hardware, software and mindware for sustainable ecosystem development: principles and methods of ecological engineering in China. Ecol. Eng. 11 (1-4), 277-289.

Wang, R.S., Li, F., Hu, D., Li, B.L., 2011. Understanding eco-complexity: social-economic-natural complex ecosystem approach. Ecol. Complex 8 (1) 15-29.

Wu, X.F., Wu, X.D., Li, J.S., Xia, X.H., Mi, T., Yang, Q., Chen, G.Q., Chen, B., Hayat T., Alsaedi, A., 2014a. Ecological accounting for an integrated "pig-biogas-fish" system based on emergetic indicators. Ecol. Indic. 47, 189-197.

Wu, X.X., Lv, M., Jin, Z.Y., Michishita, R., Chen, J., Tian, H.Y., Tu, X.B., Zhao, H.M., Niu, Z.G., Chen, X.L., Yue, T.X., Xu, B., 2014b. Normalized difference vegetation index dynamic and spatiotemporal distribution of migratory birds in the Poyang Lake wetland, China. Ecol. Indic. 47, 219-230.

Yao, L., Liu, J.R., Wang, R.S., Yin, K., Han, B.L., 2014. Effective green equivalent-a measure of public green spaces for cities. Ecol. Indic. 47, 123-127.

Yu, Y., Feng, K.S., Hubacek, K., 2014. China’s unequal ecological exchange. Ecol. Indic. 47, 156-163.

Zhang, B., Chen, G.Q., 2014. China's $\mathrm{CH}_{4}$ and $\mathrm{CO}_{2}$ emissions: bottom-up estimation and comparative analysis. Ecol. Indic. 47, 112-122.

Zhao, C.F., Chen, B., Hayat, T., Alsaedi, A., Ahmad, B., 2014. Driving force analysis of water footprint change based on extended STIRPAT model: evidence from the Chinese agricultural sector. Ecol. Indic. 47, 43-49.

Zucaro, A., Rip, M., Mellino, S., Ascione, M., Ulgiati, S., 2014. Urban resource use and environmental performance indicators: an application of decomposition analysis. Ecol. Indic. 47, 16-25.

Guest Editors

Bin Chen

State Key Laboratory of Water Environment Simulation, School of Environment, Beijing Normal University, Beijing 100875, China

Rusong Wang

State Key Laboratory of Urban and Regional Ecology, Research Center for Eco-Environmental Sciences,

Chinese Academy of Sciences, Beijing 100085, China E-mail addresses: chenb@bnu.edu.cn (B. Chen), wangrs@mail.rcees.ac.cn (R. Wang). 